\title{
LEADERSHIP AND MANAGEMENT IN THE TIME OF PANDEMICS
}

\author{
DS Briggs AM, Editor in Chief
}

I proposed that I would start this editorial with the phrase 'that we live in interesting times...'given the ongoing challenge to all is the Covid_19 pandemic. The alleged origin of the phrase is said to be from a Chinese curse 'may you live in interesting times' but is found not to be directly attributable to a Chinese source, but it does use irony to suggest we are living in difficult and challenging times. It was subsequently used by the likes of Joseph Chamberlain and more recently in the 1960s by the then USA President John F Kennedy. [1] Either way most of us know that pandemics, dissent, war, and environmental disasters are not new and recent, but have occurred throughout history and are repeated often enough for most of us to have some experience or memories of those events.

So, our interesting times are now framed by Covid-19, how it occurred, differences within states in countries like Australia and in nation states across the world. Everyone is giving everyone else advice, expert or not, to the extent that we need to now consistently define advice. That is as to that which is evidence based or from informed sources (mostly government), from 'trusted sources' in some cases a media source and the great 'pile on' from social media! We have now entered the vaccinationstage of the simple proven stages that are mostly agreed to be social distancing, personal hygiene and self-isolation if required, testing and contact tracing.

The vaccination stage both in Australia and globally is having its moments based on the sheer logistics of supply and on what type of access is available, to what 'at risk' groups and age groups order of vaccinating and, to what type of vaccine we might receive. That advice does and is changing as circumstances change. Our advice at the national level is considered and expert. At the State level that advice is sometimes different and inconsistent with some political and bureaucratic leader's intent on border closures and lockdowns without scientific evidence to support that approach. I will come to that circumstance in a moment, but the advice of this Journal is enshrined on the cover and can succinctly be expressed as:

'The best vaccine you can have is the one you have now.'

In Australia we do have the time and space to be measured in our individual responses and if people have individual concerns, they should discuss them with their general practitioner.

I know return to those politicians and bureaucrats that close borders and enact lockdowns at whim and who deprive freedom of access to hospitals, funerals and weddings and lawful employment or business while allowing mass audiences at some sporting events. As I write all these actions are occurring with some rapidity. It seems that only some of our political and bureaucratic leaders, mostly at the national level continue to act with confidence, surety and in a measured way.

I use some quotations that I have kept by me in my professional lifetime, to express some dissatisfaction evident in our communities about the variability of leadership. I also do so with apologies to the politicians and bureaucrats who are doing a god job for us from the centre ground. To the others I quote from a phrase often but incorrectly attributed to Petronius Arbiter 210 BC:

We trained hard... but it seemed that every time we were beginning to form up into teams, we would be reorganized... I was to learn later in life that we tend to meet any new situation by reorganizing; and what a wonderful method it can be for creating the illusion of progress while producing confusion, inefficiency, and demoralization.

Charlton Ogburn 1957 [2] 
It is essential for men of science to take an interest in the administration of their own affairs or else the professional civil servant will stepin-and then the Lord help you.

Rutherford, Ernest (First Baron Rutherford of Nelson) [3]

The above phrases are the riposte to those who I think disturb most sensible thinking people. This brings into context the importance of leadership and management in how we might meet and resist challenges to our health systems.

In an interesting promotion of a book entitled 'You don' $t$ need an MBA: Leadership Lessons That Cut through the Crap' In the Australian Newspaper of 29th May 2021, the books author Alicia McKay starts by quoting Elon Musk as saying he hires people despite them having an MBA and not because they might have one. He apparently says, 'top leaders spend too much time in front of spreadsheets and at meetings and not enough time thinking creatively and making things happen.' [4]

This is not a new perspective on MBAs and in this Editors recent experience participating in external course curriculum advisory committees at two different Australian universities the MBA Health is again under active consideration. Personally, I think there is a place and space for both MBAs with health context and Master of Health Management (MHM) delivered directly out of Health Faculties however titled. My one caution is that healthcare organisations are relatively unique and different, they are dominated by a vast range of highly skilled health professionals, many of them, working autonomously, yet in the modern world of ageing populations and increased burdens of disease we need them to be proficient team members. Importantly, we also require them to be proficient managers and leaders.

The essential difference between healthcare organisations and other commercially orientated organisations is context and the differences and tensions between the differing logics of each of the professions and that of managers. These differences are significant and that is perhaps why most health management programs are context specific and are located at the tertiary level, in faculties of health and medicine, however described.

McKay [4] emphasises that the 'strategic capacity of our leaders is the single - most important determinant of personal and organisational success.' Importantly, strategic leadershipjust happens to be 'all about context'. According to McKay [4] this means asking 'What are we not seeing? Being strategic requires five critical skills around being flexible, making good decisions, being a systems thinker, being focused and being an influencer.

In the context of this Editors earlier research on the impact of health reform on senior managers and leaders the findings were enshrined in the SHAPE Declaration $[5,6]$ as being about capability of being:

Trained and experienced to lead and manage in a range of differing health systems and organisational arrangements. Possessing a deep contextual understanding of health systems, public policy, professional cultures, and politics. Having competency in organisational sensemaking as negotiators of meaning, active participants, constructors, organisers, and persuaders within health systems. Being drawn from a range of backgrounds, both clinical and nonclinical experience and qualifications, demonstrating more than one logic. Leaders and managers need to understand how clinical work should be structured, managed, and work actively with those clinicians and others to deliver coherent, well managed health services.

In this issue, Olley [7] provides a further theoretical contribution to the importance of management and leadership by referencing 'authentic leadership' that which is based on self-awareness, relational transparency. balanced processing and internalised moral perspectives. I encourage you to read the article provided by Olley, particularly that around authentic leadership. You will see some consistency around ethics, values and professionalism in the articles quoted here that is further reinforced in the commentary by Neale Fong [8] National President of ACHSM in this issue.

This discussion is not only important to the health sector but also relevant to the tertiary university sector that appears to be in a contractionary phase following the loss of international students. We should not need to remind them that the greatest challenge to the health system now is a lack of a sufficiently educated, trained, and skilled health workforce. In Australia, one has only to look at the findings of the differing Royal Commissions into aged care, disability, mental health, and suicide to understand the potential for the vocational and tertiaryeducation sectors. 
One has only to live in rural and remote communities to experience the paucity of the health workforce.

Let us encourage the education and professional development of health professionals and others towards being both ethical and value based and authentic in meeting the management and leadership challenges of health systems.

DS Briggs AM

Editor in Chief

\section{References}

1. Wikipedia - Joseph Chamberlain available from https://en.wikipedia.org/wiki/May you live in interesti ng times. 22nd June 2021

2. Ogburn (1911-1998) in "Merrill's Marauders: The truth about an incredible adventure" in the January 1957 issue of Harper's Magazine from https://quotes.yourdictionary.com/author/quote/5917 15. 22 nd June 2021

3. CITATIS. Ernest Rutherford Quotes from https://citatis.com/a19379/. 22nd June 2021

4. McKay A. May 29th, 2021. 'Why an MBA won't get you through today's business world'. The Australian Newspaper.

5. Briggs DS. Smyth A. Anderson JA. (2012). In Search of Capable Health Managers: what is distinctive about health management and why does it matter? Asia Pacific Journal of Health Management 2012; 7: 2

6. Briggs DS (2008). SHAPE Declaration on the Organisation and Management of Health Services: a call for informed debate in Asia Pacific Journal of Health Management 3:2 10-13.

7. Olley R. (2021). A narrative review of power and influence theories of leadership. Asia Pacific Journal of Health Management 6:2

8. Fong N. (2021). Commentary on Leadership. Asia Pacific Journal of Health Management. 6:2 